\title{
Subarachnoidal migration of intraocular silicone oil
}

\author{
Francisco J. Ascaso ${ }^{1,2}$ • Andrzej Grzybowski ${ }^{3,4}$
}

Received: 8 February 2017 / Accepted: 20 February 2017 / Published online: 3 March 2017

(C) The Author(s) 2017. This article is published with open access at Springerlink.com

\section{Dear Editor,}

We have read with interest the article "Subarachnoidal migration of intraocular silicone oil" published by Cebula et al. [1]. We would like to congratulate the authors for the diagnosis and successful conservative management of two cases of such a rare complication.

We believe, however, that some discussion of this article is needed. Thus, we must clarify that what the authors describe as the posterior chamber of the eye really corresponds to the vitreous cavity. In fact, the posterior chamber, a narrow space located behind the iris but anterior to the lens, is a part of the ocular anterior segment. It is filled with aqueous humor and should not be confused with the vitreous chamber, which is part of the posterior segment of the eye and is occupied by vitreous humor.

We agree with the authors that the increased intraocular pressure or the presence of congenital optic nerve anatomical abnormalities might have caused intracranial migration of $\mathrm{SiO}$ from the vitreous space into the subarachnoidal space [2]. Nevertheless, they provide no information about either the aspect of the optic disc or the type and viscosity of the $\mathrm{SiO}$ employed in both cases. These clinical data regarding the presence of any of these predisposing factors in these patients might have played a crucial role in physical silicone migration [3].

Open Access This article is distributed under the terms of the Creative Commons Attribution 4.0 International License (http:// creativecommons.org/licenses/by/4.0/), which permits unrestricted use, distribution, and reproduction in any medium, provided you give appropriate credit to the original author(s) and the source, provide a link to the Creative Commons license, and indicate if changes were made.

\section{References}

1. Cebula H, Kremer S, Chibbaro S, Proust F, Bierry G (2017) Subarachnoidal migration of intraocular silicone oil. Acta Neurochir (Wien) 159(2):347-348

2. Grzybowski A, Pieczynski J, Ascaso FJ (2014) Neuronal complications of intravitreal silicone oil. an updated review. Acta Ophthalmol 92(3): 201-204

3. Grzybowski A, Ascaso FJ (2016) Migration of intraocular silicone oil to CNS: the role of elevated intraocular pressure and congenital optic nerve abnormalities. Clin Neuroradiol 26(1):127
Francisco J. Ascaso

jascaso@gmail.com

1 Department of Ophthalmology, Hospital Clínico Universitario Lozano Blesa, Av. San Juan Bosco 15, 50009 Zaragoza, Spain

2 Aragon Health Research Institute (IIS Aragon), Zaragoza, Spain

3 Department of Ophthalmology, Poznan City Hospital, Poznan, Poland

4 Chair of Ophthalmology, University of Warmia and Mazury, Olsztyn, Poland 